\title{
Pueblos originarios y discriminación: ¿Qué límites impone la no-discriminación a la soberanía popular? ${ }^{1}$.
}

First Nations and discrimination: What limits does non-discrimination impose on popular sovereignty?.

\section{Enrique Camacho Beltrán}

Colegio de Filosofía, Facultad de Filosofía y Letras. Universidad Nacional Autónoma de México (MÉXICO)

CE: enrique.camacho@comunidad.unam.mx / ID ORCID: 0000-0001-6876-8460

DOI: $10.32870 /$ sincronia.axxiv.n77.27a20

Esta obra está bajo una Licencia Creative Commons Atribución-NoComercial 4.0 Internacional $B Y \cdot N C$

Recibido: 01/09/2019

Revisado: $07 / 11 / 2019$

Aprobado: $13 / 12 / 2019$

\section{RESUMEN}

Con frecuencia, la autonomía de los pueblos y el respeto a los derechos humanos establecen un dilema: o se reconoce la autonomía (porque el no hacerlo sería discriminatorio) o se hace cumplir el principio de no-discriminación a costa de la autonomía de los pueblos. Pero sugiero que el dilema se

\footnotetext{
${ }^{1}$ Muchas gracias a las audiencias del Congreso Nacional de Investigación sobre Derechos Humanos 2017. Particularmente agradezco a Luis González Plasencia por sus iluminadores comentarios. Agradezco el apoyo de la Red Nacional de Enseñanza, Investigación e Intervención en Derechos Humanos; muy especialmente a Mario Alfredo Hernández. Estoy en deuda también con el proyecto UNAM-DEGAPA-PAPIIT IG400216, Derechos Sociales y Justicia Social; especialmente con Juan Antonio Cruz, Valeria López Vela y Sandra Anchondo por sus incisivas preguntas y críticas. Adicionalmente agradezco a los alumnos de doctorado de la Escuela Libre de Derecho de Puebla (Asignatura de Filosofía del Derecho 2019) por su lectura crítica y sugerencias puntuales. Particularmente estoy en deuda con Raúl Rodríguez Eguibar, con los hermanos Marco y Víctor Arredondo y con Álvaro Morales. Agradezco también a una o un lector(a) anónimo(a) por sus observaciones y cuidadosos comentarios. Finalmente agradezco a Mauricio Rojas Mendoza por su generoso apoyo editorial.
} 
desinfla cuando distinguimos el daño especial que hace la discriminación y cuando distinguimos el interés que tienen los miembros de un pueblo de tener una buena vida, del interés fundamental que tenemos todos de vivir bien. El uso de estas categorías dworkineanas permite ver que el daño tan distinguible que provoca la discriminación, requiere moralmente el abandonar la pretensión de "sentirnos como en casa" en nuestros pueblos (es decir parte de las condiciones que proporcionan una buena vida) y aceptar las condiciones que hacen posible que todos vivan bien.

Palabras clave: Discriminación. Autonomía Indígena. Multiculturalismo. Legitimidad Democrática.

\section{ABSTRACT}

Often, first nation's political self-determination and the respect of human rights poses a dilemma: either we respect and recognize their autonomy, or we ban acts of discrimination even though we jeopardize their autonomy. But here I suggest that this dilemma deflates when we clarify the special nature of what's harmful with discrimination, and when we use the dworkinean categories to distinguish the interest members have in having a good life, from the fundamental interest we all have in living well. What's harmful with discrimination morally requires we abandon the aspiration of "feeling at home" in our peoples and accept the conditions that make possible for everyone else to live well.

Keywords: Discrimination. First nations' self-determination. Multiculturalism. Democratic legitimacy.

A mediados del año 2019 comenzó el proceso de consulta para para la Reforma Constitucional y Legal sobre Derechos de los Pueblos Indígenas y Afromexicano con respecto - entre otras cosas- de la personalidad jurídica de los pueblos y los derechos de las mujeres que son miembros de estos pueblos. Por ello resulta interesante preguntarse por el cómo la normatividad de los pueblos indígenas puede cohabitar con la normatividad del estado mexicano en su conjunto. ¿Cuáles son nuestros deberes morales con respecto de esta tensión?

Una manera de plantear esa pregunta es identificando y ordenando los intereses en disputa para poder determinar cuáles de ellos dan lugar a obligaciones de proteger esos intereses, de una 
manera en la que identifiquemos la importancia relativa de unos intereses sobre de otros. En el caso que nos ocupa, la mayoría de las personas tenemos un interés legítimo y muy poderoso de que las instituciones públicas reflejen nuestras convicciones morales importantes. Los miembros de los pueblos comparten ese interés cuando pretenden que los usos y costumbres que articulan sus principios y valores morales tengan un reconocimiento jurídico. En parte, el que seamos capaces como comunidad de darnos una buena vida depende en alguna medida de la capacidad que tengan las instituciones locales de hacernos sentir como en casa. Es decir, cuando los códigos, reglamentos y leyes que regulan la convivencia reflejan hasta cierto punto nuestros valores y principios aumenta nuestro bienestar. El problema es que la mayoría de los mexicanos tenemos ideas bien distintas acerca de qué es la buena vida, por lo que los órdenes normativos $-\mathrm{y}$ los principios y valores subyacentes - pueden entrar en conflicto e inclusive resultar irreconciliables.

La literatura Angloamericana sobre la justicia con frecuencia representa este conflicto como el enfrentamiento de distintas concepciones del bien frente a las cuales las instituciones han de ser imparciales. ${ }^{2}$ Pero esa literatura fue planteada en condiciones de pluralismo razonable; mientras que en México el problema puede describirse más bien como una forma de relativismo cultural. ${ }^{3}$ México es pluricultural, lo que significa que las personas no sólo difieren con respecto de lo que es valioso de la vida, sino que además tienen concepciones distintas - y a veces irreconciliables-de los tipos de persona que resultan valiosos. Por ejemplo, hay lugares donde los hombres valen más que las mujeres, los muxes ${ }^{4}$ valen más que otros hombres, la autoridad justa y legítima es ejercida por una

\footnotetext{
2 Véase por ejemplo, Dworkin (2011, pp.195-202); Scanlon, 1998, What we owe to each other pp. 8, 66, 68, 199); Rawls (2001, pp. 3, 4, 33, 40). Para una discusión acerca de las buenas razones en la vida pública véase Muñoz (2017, pp. 1939).

3 Por ejemplo, Muñoz (2017); Velasco (2017); Camacho (2017); Ruiz (2017). Para una discusión acerca de los límites del multiculturalismo y su aplicación al contexto latinoamericano y mexicano véase Muñoz (2017). Particularmente los textos de Andrés Moles, Ángel Ruiz y el mío propio.

${ }^{4}$ Se denomina muxe ('mushe') al género que define a una persona nacida con sexo genital masculino que asume roles femeninos dentro de la comunidad zapoteca. En una familia tradicional, el muxe todavía suele ser considerado por su madre como "el mejor de sus hijos" ya que el hijo muxe nunca abandona a los padres en los momentos difíciles de la vida: la vejez y las enfermedades. Véase por ejemplo Rymph (1974).
} 
sola persona, etc. Por ello no es para nada claro que esa aproximación sea apropiada para el caso mexicano. ${ }^{5}$

Considere el caso general de los pueblos indígenas. La Constitución (CPEUM) establece que "pueblos indígenas son aquellos que descienden de poblaciones que habitaban en el territorio actual del país" (Constitución Política de los Estados Unidos Mexicanos, 2019, Artículo $2^{\circ}$ ). Hay cuando menos 24.4 millones de personas de 3 años y más que se identifican a sí mismas como indígenas. La mayor parte de estas personas viven aún en sus pueblos originarios; solamente $11.7 \%$ de la población que habla lengua indígena es migrante absoluto; es decir, viven en una entidad federativa distinta a la de su nacimiento (Instituto Nacional de Estadística, Geografía e Informática, 2015). Esto es motivo de orgullo pero también es fuente de conflicto cuando los miembros de esos pueblos desean que sus convicciones acerca de lo que es valioso de la vida - lo que contribuye a tener una vida buena - se reflejen directamente en las instituciones del cabildo, municipio o el Estado en el que viven procurando evitar que el resto de los mexicanos fuera de la comunidad modifiquen legalmente sus costumbres. Ellos reclaman su derecho de autodeterminación política que significa que como comunidad pueden controlar su destino en común (Walzer, 2004, pp. 13, 43). Por eso me pregunto ¿Cómo puede el Estado mexicano proteger los derechos humanos de todos, en el sentido de que sus instituciones no discriminen a nadie y al mismo tiempo respetar los derechos humanos de los pueblos reconociendo el interés legítimo que tienen los mexicanos en que sus instituciones reflejen su moralidad, aún si su moralidad incluyera algunas ideas discriminatorias? ${ }^{6}$

En las condiciones que nos son familiares a nosotros, que son aquellas que permean la consulta para la reforma constitucional, pareciera que o se permite la autonomía (algunas veces a costa de los derechos humanos) para evitar la discriminación en cuanto al disfrute de los derechos

\footnotetext{
${ }^{5}$ Sobre la diferencia entre el problema del pluralismo razonable y el relativismo véase Camacho 2017.

${ }^{6}$ Se trata de un dilema que mencioné en otro texto como ejemplo de la superficialidad de algunos planteamientos multiculturalistas. Al respecto, consúltese Camacho (2017, pp. 74-76). En ese texto estaba yo enfocado en el problema metodológico del observador en las ciencias sociales y el uso de la hermenéutica; por lo cual dejé el dilema sin abordar. Ahí desarrollo con más amplitud algunas aristas de este problema. En este texto sin embargo me concentro en sólo en cierto tipo de límites morales de la autodeterminación política de los pueblos originarios.
} 
políticos; o se hace cumplir el principio de no-discriminación en los pueblos (sobre todo en el caso de los derechos de las mujeres y algunas minorías religiosas o sexuales) a costa de los derechos políticos de los pueblos. Para desinflar el dilema propongo en la primera sección, insistir que no todo interés poderoso equivale a un derecho y distinguir dos maneras distintas de valorar la vida común: darse la buena vida y vivir bien. Después en la segunda sección aventuro que la legitimidad democrática requiere las condiciones para que una pluralidad de grupos pueda vivir bien, pero no requiere que todos se sientan como en casa y se den la buena vida. En la tercera sección reviso algunas objeciones.

Antes de proceder a los argumentos, es preciso hacer algunas notas acerca de la aproximación y los límites de la investigación. En primer lugar el problema a primera vista parece que el problema que planteo requiere ser abordado desde los estudios inter y transdisciplinarios. En efecto el dilema se replica en lo legal, lo moral, lo cultural, lo social, lo económico, lo ético y en muchas otras áreas. Pero en el espacio de este artículo no puedo abordar ese tipo de estudio. Antes bien me propongo ubicarme en una delgada capa de análisis en la que conviven la filosofía del derecho y la filosofía moral y política. ${ }^{7}$

Mi idea aquí es explicar la naturaleza de la tensión entre los derechos de autodeterminación política de los pueblos y el principio de no-discriminación utilizando algunas definiciones de trabajo acerca del carácter moral de la vida en comunidad; y estableciendo el contexto metodológico y teórico en el cual funcionan esas definiciones. Sin embargo, aún bajo esa delimitación el problema puede parecer desbordante porque puede estudiarse desde distintos niveles de análisis. Por ejemplo, puede preguntarse cuáles son las normas e instrumentos legales que se utilizan en condiciones plurijurídicas o de sistemas jurídicos paralelos. También podríamos cuestionar qué tipo de deberes morales establecen obligaciones en las condiciones que impone el tipo de relativismo moral que opera bajo sistemas de valores y principios inconmensurables. ${ }^{8}$ Pero mi objetivo es más modesto aún. Pretendo solamente organizar la discusión en una de sus dimensiones y que al hacerlo el dilema no

\footnotetext{
${ }^{7}$ La relación entre el derecho por un lado y la filosofía moral y política es complicada y objeto de enormes controversias. Para los fines de este trabajo basta con que esa relación sea contingente y algunas veces valiosa e importante, aunque no sea necesaria.

${ }^{8}$ Muchas gracias a Víctor Hugo Arredondo por ayudarme a precisar este punto.
} 
sea tan inabordable e intimidante como parece hasta ahora. Para hacerlo no pretendo agotar la perspectiva moral o la legal; sino que pretendo referirme a un conjunto muy discreto de deberes morales de grupo que tienen cierta trascendencia legal o bien a deberes morales de grupo que tienen una trascendencia legal. Por ejemplo, si un sistema legal considera que un grupo es portador de derechos, se pueden generar males morales que no hubieran existido si no se hubiera empoderado legalmente al grupo en primer lugar. Similarmente si un grupo tiene derechos legales la violación de estos puede tener un peso moral. ${ }^{9}$ Así pues, en este trabajo me pregunto específicamente por incorrecciones morales que surgen de proteger legalmente la autonomía de los pueblos indígenas con respecto del principio de no discriminación.

\section{Derechos Humanos y Pueblo.}

Voy a partir de algunas consideraciones previas. La teoría política reconoce varios tipos de agentes colectivos (grupos con carácter moral); es decir sujetos de responsabilidades y derechos corporativos: típicamente los Estados o las naciones. Uno de estos agentes sociales es el pueblo (Moore, 2015, p. 53). Pueblo no se refiere a la población que está sujeta al poder coercitivo de un Estado y que intenta ejercer su soberanía popular frente a él, porque eso sería más bien la ciudadanía. Tampoco se refiere a los miembros de la mayoría nacional que ven su cultura reflejada y protegida en las instituciones coercitivas del Estado, porque esos serían más bien los compatriotas. Al contrario, pueblo se refiere a una comunidad que tiene agencia social y una identidad política común, pero donde esta agencia e identidad no dependen del poder institucional centralizado como en el caso del Estado o de la nación, sino que surgen espontáneamente porque la comunidad está políticamente movilizada de manera orgánica; es decir mediante la acción política de sus miembros que se traduce en una acción colectiva (Moore, 2015, pp. 53-55, 195).

Ahora si recordemos el dilema que nos ocupa: el artículo segundo de la constitución reconoce el derecho de autodeterminación de los pueblos indígenas para aplicar sus propios sistemas

\footnotetext{
${ }^{9}$ Acerca de deberes de grupo morales que son legalmente dependientes véase Jones (1999) y (2016)
} 
normativos. Al mismo tiempo establece la condición de que los pueblos indígenas respeten los derechos humanos, las garantías individuales y la dignidad e integridad de las mujeres. ${ }^{10} \mathrm{El}$ problema principal es que la constitución no dice cómo estas dos cosas pueden ser posibles al mismo tiempo. No parece ni probable ni posible que congruentemente los pueblos puedan obedecer sus sistemas normativos con su estructura tradicional y obedecer también la constitución del país con su énfasis en los derechos humanos. Pero al mismo tiempo eliminar la autodeterminación que la constitución les concede a estos pueblos sería discriminatorio al negarles el control sobre su vida comunitaria.

Sirvan como ilustración los dos ejemplos más familiares: En 2014 la suprema corte de justicia reconoció la facultad de la comunidad indígena purépecha de Cherán, Michoacán, de ejercer su autodeterminación política y elegir según sus usos y costumbres, a sus autoridades municipales. Este reconocimiento incluye de manera central la capacidad de las autoridades electas de interponer controversias constitucionales en contra de reformas que consideren una violación a los derechos de los habitantes. Es decir, en esas condiciones la comunidad de Cherán goza, en principio de iguales derechos con respecto de cualquier otro municipio de la república, de tal forma que tiene la posibilidad de demandar cuando considere que una reforma legal atenta contra la comunidad que representa. ${ }^{11}$ En este caso el reconocimiento a los usos y costumbres de la comunidad ha sido instrumental para empoderar a sus miembros en la lucha contra el crimen organizado. Pero el ejercicio de este tipo de autodeterminación política produce frecuentemente violaciones a los Derechos Humanos. Por ejemplo, en varios municipios de Oaxaca los jefes de la comunidad deciden por quién votan todos los miembros de la comunidad. En San Juan Chamula los líderes indígenas han

\footnotetext{
${ }^{10}$ En su Artículo segundo la CPEUM “Aplicar sus propios sistemas normativos en la regulación y solución de sus conflictos internos, sujetándose a los principios generales de esta Constitución, respetando las garantías individuales, los derechos humanos y, de manera relevante, la dignidad e integridad de las mujeres. La ley establecerá los casos y procedimientos de validación por los jueces o tribunales correspondientes." Pero existe poca claridad acerca de cómo son aplicables sistemas normativos basados en jerarquías sociales que le atribuyen un valor diferenciado a la vida de las personas de manera que sean estos armonizables con la CPEUM.

${ }^{11}$ Véase: https://www.bbc.com/mundo/noticias-america-latina-37644226 Consultado el 4 de diciembre de 2019.
} 
expulsado a cientos de campesinos por no profesar la religión católica, o por no acatar sus ordenanzas. ${ }^{12}$

Conflictos como estos pueden interpretarse de manera aproximada como conflicto de deberes. En este texto voy a asumir -en espera de que no sea demasiado controvertido-que los derechos humanos y la protección que ellos ejercen contra la no-discriminación establecen cuando menos tres tipos de responsabilidades a las instituciones políticas y aquellos sujetos a esas instituciones. La primera de ellas es que México es un Estado de composición pluricultural y por ello reconoce el derecho de autodeterminación política a los pueblos que lo forman. La segunda es un corolario de la primera: el Estado mexicano debe buscar una manera legítima e incluyente de resolver el dilema que ese tipo de autonomía plantea. Esto es, debe buscar la manera de que todos incluyendo los miembros de los pueblos que forman nuestro país - puedan someterse a las leyes y el arreglo constitucional legítimo sin que por ello sientan que abandonan sus principios más básicos y que por ello están dominados por la mayoría (Dworkin, 2001, p. 205). Pero en tercer lugar también establece responsabilidades que aplican a todos los mexicanos. Los mexicanos debemos estar en la disposición de apoyar e identificarnos con el arreglo político y social que permita que todos los mexicanos puedan estar incluidos. ${ }^{13}$ Esto incluye entender que ningún arreglo político y social puede reflejar las convicciones morales de todos los habitantes del país y que ningún Estado puede reflejar la moralidad de una sola persona o de un grupo, aunque este sea mayoritario.

Pero entonces el dilema se vuelve aún más agudo. ¿Cómo podría si fuera el caso, un pueblo, con convicciones morales claras y fuertes apoyar e identificarse responsablemente con un arreglo político que sin embargo no puede reflejar nunca íntegramente esas convicciones? ¿No sería propio de un pueblo con autodeterminación política no solo renegar sino oponerse absolutamente a un régimen político que no refleje sus convicciones morales más importantes y centrales? ¿Significa entonces que todos aquellos que se atreven a vivir de acuerdo con sus convicciones nunca podrán

\footnotetext{
${ }^{12}$ Véase: $\quad$ https://frayba.org.mx/historico/archivo/informes/030101 informe_especial_sobre chamula_frayba.pdf Consultado el 16 de diciembre del 2017.

${ }^{13}$ Véase por ejemplo Kolodny (2014).
} 
vivir de acuerdo con la constitución o ser ciudadanos modelo o patriotas, porque no pueden identificarse con las leyes que regulan la convivencia; y que justamente aquellos sin convicciones morales sean precisamente los que ha de considerarse ciudadanos modelo porque sólo así es posible identificarse con el orden normativo del Estado?

Creo que el conflicto presente en aquel dilema puede enfrentarse mejor -si bien no disolverse del todo- si aclaramos dos confusiones comunes. En primer lugar, no todo interés equivale a un derecho, aunque ese interés sea colectivo y organizado. Por ejemplo, yo tengo un interés dolorosamente poderoso de que el reggaetón deje de existir, pero ese interés, por muy intenso que sea nunca se traduce en el derecho a impedir que la gente lo escuche, lo baile, lo cante y lo componga. Como mencioné anteriormente, típicamente, una de las funciones más básicas que se le ha atribuido al Estado, es la de contener o limitar el particularismo de los individuos; es decir la tendencia de buscar la satisfacción de los intereses particulares por cualquier vía, inclusive la institucional, aun a costa de los intereses de los demás, sobre todo cuando se tiene la ventaja, los recursos o el poder de imponer esos intereses (Durkheim, 1966, pp. 87-95). Pero esto también aplica a los intereses colectivos. Suponga que me asocio con todos los detractores del reggaetón en México y comenzamos a organizarnos de manera piramidal y sofisticada, hasta que en cada estado y municipio tenemos una representación que nos da recursos para reunirnos en todos lados, odiar el reggaetón juntos y escuchar a Bach. Aún en esas condiciones, mi interés y el de las personas con las que me asocio, no puede traducirse en un derecho colectivo de imponer nuestro gusto musical a los demás.

Ceteris paribus, es cierto que ningún Estado legítimo debería requerir que los ciudadanos abandonen sus convicciones acerca de lo valioso de la vida para participar en la vida pública. Hacerlo significaría no tratarlo con igual consideración, discriminarlo por sus convicciones, sus ideas o su fe. Pero esta igualdad de trato no requiere que el Estado refleje íntegramente las convicciones de un ciudadano porque hacerlo significaría faltar a la igualdad de trato con el resto de las personas.

Para ponerlo más claro, nadie (que no sea un tirano) puede razonablemente exigir vivir en una sociedad donde las instituciones reflejen íntegramente sus convicciones y al mismo tiempo insistir 
que él mismo es consecuente con sus propias convicciones morales. Lo mismo puede decirse de los grupos sociales. Ningún grupo social (que no sea un grupo de oligarcas) puede exigir que todos vivan con respecto a sus normas, sin someter arbitrariamente a otros grupos.

La segunda confusión está en no distinguir darse la buena vida de vivir bien (Dworkin, 2011, pp. 196-8). Se trata de dos maneras de valorar la vida colectiva e individual de las personas que tomo de Dworkin, pero que extrapolo para determinar qué es lo que la moralidad pública requiere de los ciudadanos de los pueblos con respecto al dilema que planteo. Todos tenemos una idea más o menos clara de aquello que nos proporcionaría una buena vida: la comida de mamá, los paisajes de nuestro pueblo, los viajes, la comida reconfortante. En lo colectivo nos ayuda a tener una buena vida que todos hablen nuestra lengua, que no exista incertidumbre económica o política, que nuestro entorno esté modelado según nuestra cultura y todas esas cosas que en lo individual y en lo colectivo nos interesan. Pero no pensamos que debamos tener todas y cada una de las cosas que nos dan una buena vida para vivir bien. Al contrario, sabemos que con frecuencia tenemos que sacrificar cosas que nos dan una buena vida para vivir bien. Por ejemplo, los estudiantes sacrifican el quedarse en cama en una mañana fría y lluviosa de invierno para asistir a sus clases de filosofía o los noruegos sacrifican una parte importante de lo que podrían ahorrar o invertir para mantener su estado de bienestar. Es decir, para vivir bien, necesitamos una visión crítica de todas las cosas que nos dan la buena vida que nos permite elegir entre distintas cosas que nos dan la buena vida; inclusive entre distintas concepciones del valor y varios planes de vida. Sin embargo, hay que notar que sería imposible vivir bien si no tenemos cuando menos algunas de las cosas necesarios para darnos la buena vida. En síntesis, vivir bien, incluye muchos sacrificios porque vivir bien significa hacernos responsables por hacer algo de provecho, algo valioso con nuestras vidas.

En lo que sigue voy a utilizar estas categorías del valor para desinflar el dilema que me he planteado. El problema con estas categorías es que, aunque la distinción es clara, los límites son difusos y las caracterizaciones muy vagas. Parece difícil aproximar definiciones de trabajo acerca de 
estas áreas del valor. ${ }^{14}$ Esto hace que, en condiciones determinadas el intento por definir estos conceptos sea en ocasiones contraproducente para los propios fines de un trabajo como este. Se trata en realidad una propiedad muy familiar de conceptos valorativos como a los que me refiero, misma que fue descrita en los cincuentas en el famoso trabajo de Gallie "Conceptos esencialmente impugnados" (Gallie, 1998). Este tipo de nombres, se utilizan en discusiones sobre tensiones, dilemas o condiciones problemáticas que todas las personas pueden reconocer y con respecto de la cual existe polisemia con respecto de nociones centrales para la discusión.

En el caso darse la buena vida y vivir bien hay un acuerdo general sobre la distinción entre una manera de valorar las cosas de manera directa, por ejemplo instrumental o intrínsecamente y una manera de valorarlas críticamente; pero hay una controversia enorme acerca de la mejor manera de aplicar esta distinción a distintos contextos. ${ }^{15}$ Pero eso no debe preocuparnos porque la aplicación de esas maneras de valorar excede los confines de este trabajo. Mi único propósito aquí es notar, que cualquiera que sea la concepción exacta de la distinción que adoptemos, la sola distinción contribuye a desinflar el dilema. Por ejemplo, uno de los aspectos sustanciales de vivir bien es ser parte de una comunidad que establece las condiciones de posibilidad para las personas vivan bien y tengan una buena vida. Pero vivir bien establece límites en la buena vida que nos demos, porque no podemos tener todos nuestros intereses satisfechos, de la misma manera que tener una buena vida establece límites en nuestra capacidad de vivir bien, por ejemplo, cuando no tenemos los medios materiales suficientes para hacer algo valioso de nuestro tiempo. Cuando entendemos que la igualdad no significa que todos tengamos derecho a que el Estado refleje íntegramente las convicciones nuestras o nuestro grupo y cuando entendemos que no todo interés justifica la creación de un derecho, porque no todo interés en tener una buena vida es necesario para vivir bien; entonces podemos explicar de qué manera alguien con convicciones morales fuertes puede responsablemente apoyar un régimen

\footnotetext{
14 Muchas gracias a Rebeca Alcaide, Víctor Arredondo, Marco Antonio Arredondo, y a Raúl Rodríguez Eguibar del Doctorado de la Escuela Libre de Derecho de Puebla por discutir este punto conmigo en mi clase de filosofía del derecho del 2019.

15 Por ejemplo, de manera muy celebre J.S. Mill (1997) sostuvo un tipo de distinción similar en contra del tipo de consecuencialismo sostenido por J. Bentham. Véase Mill, El Utilitarismo, pp. 45-48.
} 
político a pesar del hecho de que éste no refleje íntegramente todas y cada una de sus convicciones. Apoyamos responsablemente una democracia liberal, aunque no refleje íntegramente todas nuestras convicciones morales porque vivir bien no consiste sólo en darnos la buena vida y porque parte importante de vivir bien es vivir en una sociedad plural y libre en la que muchas maneras de tener una buena vida y de vivir bien sean posibles.

\section{Legitimidad Democrática y Soberanía Popular.}

Hasta ahora, he desinflado un poco el dilema al aclarar que la vida pública requiere que renunciemos a la idea de que las instituciones protejan todos nuestros intereses y a que el derecho codifique todas nuestras convicciones morales. Sin embargo, alguien podría objetar, que, en una democracia federal, las minorías se hacen mayorías en su ámbito propio local, y ese ámbito tiene que ser respetado: ¿No le reconoce la propia constitución la autodeterminación política a los pueblos indígenas? Si es así, ¿no es cierto que en una democracia las mayorías cuentan y que las minorías están obligadas a ceder a favor del bienestar del mayor número de personas?

No deja de ser atractivo, pensar que, si la mayor parte de los mexicanos en un municipio o en un pueblo piensan de la misma manera acerca de aspectos específicos de la vida pública sobre de lo que constituye darse la buena vida, entonces quizás sea deseable que el mayor número de estos realice lo más posible esos valores. Si la mayoría de los mexicanos en un pueblo o en un municipio consideran el uso de la minifalda desagradable o los matrimonios entre personas del mismo sexo reprobables, o los abortos aberrantes ¿no está la minoría, dentro de un pueblo moralmente obligada, a ceder a favor de la mayoría? Después de todo, aquellas minorías disidentes en un pueblo siempre pueden cambiar su residencia a un lugar donde sus ideas y sus prácticas sean mejor vistas por la mayoría.

Pero esta noción es equivocada. En una asociación cualquiera, la mayoría es suficiente para tomar decisiones siempre que los miembros tengan interés en permanecer en la asociación y la asociación satisfaga razonablemente el interés colectivo que motivó su formación en primer lugar. Esto es porque las asociaciones o corporaciones se distinguen de la mera agregación de individuos en 
que las decisiones obligan aún a los disidentes y a las minorías porque son ellos los que consienten en permanecer vinculados a la asociación (Searle, 1998, pp. 143-158). En cuanto una asociación deje de satisfacer sus intereses expresivos siempre pueden abandonarla para formar nuevas asociaciones. Pero una democracia liberal como México no es una asociación. Las democracias liberales no persiguen la realización de un propósito colectivo particular sino más bien son condición de posibilidad o medios para la realización de los propósitos de los grupos y los individuos (Dworkin, 2001, p. 205). Por eso las democracias liberales no son meras asociaciones, sino que son comunidades éticas que obtienen su legitimidad en parte por el hecho de que parecen necesarias para asegurar que todos tengan oportunidad de realizar alguna concepción de lo que es vivir bien, mientras que puedan razonablemente darse una buena vida (Dworkin, 2011, pp. 13-19; 196-8). Es decir, las democracias liberales federales tienen un carácter moral en parte porque permiten y mantienen la diversidad, el pluralismo y el multiculturalismo. Pero esto quiere decir que los Estados y los pueblos tampoco son corporaciones o asociaciones cualesquiera; por lo que en su caso la igualdad política y su regla de la mayoría no son siempre suficientes.

Aquí conviene hacer énfasis en una distinción que ya había hecho en la sección primera. Hay varios tipos de grupos y comunidades; pero lo que distingue los meros agregados de los grupos con derecho de asociación y de autodeterminación política es la agencia colectiva, porque es lo que permite a un grupo al mismo tiempo tomar control sobre sí mismo y hacerse responsable del uso de ese control. ${ }^{16}$ Por eso no podemos responsabilizar colectivamente al agregado de consumidores de marihuana, pero si podemos responsabilizar al Cartel del Golfo, pues el primero no tiene la estructura organizacional y corporativa que tiene el segundo. ${ }^{17}$ Ahora bien, en general los grupos con agencia y responsabilidad adquieren este estatus precisamente porque son organizaciones construidas alrededor de un fin común. El Cartel del Golfo busca adquirir ganancias mediante sus actividades criminales, Greenpeace busca proteger el medio ambiente, Boy Scouts de América busca la formación

\footnotetext{
${ }^{16}$ En esto sigo a Tuomela (2005) y a Searle (1998).

${ }^{17}$ La comparación en el ejemplo se concentra en la responsabilidad colectiva, independientemente de la responsabilidad individual. Por ejemplo, puede responsabilizarse individualmente a los consumidores de mariguana a pesar de que no se los pueda responsabilizar como un solo agente grupal. Gracias a Raúl Rodríguez Eguibar por señalarme este punto.
} 
de los jóvenes, etc. El carácter ético de estos grupos está definido por su propósito. Cuando el grupo pierde o cambia su carácter ético y funcional, entonces los miembros pueden separarse; pero una comunidad política es radicalmente distinta a estas comunidades de interés, precisamente en que típicamente no formamos parte de ellas voluntariamente y en que no están construidas alrededor de un interés común, pero aun así les atribuimos agencia y responsabilidad. ${ }^{18}$

Ahora bien, hay varias comunidades con un reclamo sustantivo por autodeterminación política. ${ }^{19}$ Típicamente los Estados, las naciones y los pueblos. La discusión acerca de cuál de estos agentes es el sujeto propio de la autonomía y la responsabilidad política es muy controvertida. Quizás sea una cuestión de grados y todos participen de este estatus político o bien quizás uno de ellos sea el sujeto político más propio y los derechos políticos de las demás comunidades deriven de que guarden la relación correcta con este sujeto propio. Pero resolver esta controversia no modifica el objeto de este trabajo. Ya sea que el estatus político de los pueblos derive de otro agente como el Estado como lo creen los Kantianos estatistas; o que los pueblos sean el agente más propio de autodeterminación política como lo cree Moore, en cualquier caso, los pueblos son comunidades políticas y no comunidades de interés; por lo que su carácter ético no puede reflejar solamente los intereses de una comunidad, sino la capacidad de la comunidad política de realizar una pluralidad de intereses. $^{20}$

Claro que hay comunidades políticas que no tienen un carácter ético sustantivo. La historia está llena de regímenes políticos cuya legitimidad está justificada por las circunstancias en las que fueran la única opción para mantener orden y establecer un gobierno efectivo en un territorio determinado (Williams, 2005, Cap. 1). Pero estas comunidades políticas no son el objeto de este trabajo. Las democracias liberales, por otro lado, pretenden tener un carácter ético sustantivo que

\footnotetext{
18 Por ejemplo, véase Wellman (2001).

19 Para una discusión, véase Margalit y Raz (1990).

${ }^{20}$ Kant pensaba que tenemos una obligación fundamental de apoyar el Estado cuando éste es justo, por lo que el Estado justo puede ejercer permisiblemente autoridad sobre cualquiera que se encuentre en su jurisdicción (1970, pp. 133, 137, 172). Véase Ripstein (2010). Son defensores contemporáneos de esta visión Ypi (2014); Buchanan (2008); Stilz (2011); y Nine (2012).
} 
establece un orden legítimo y las relaciones de justicia suficientes para permitir a todos darse una vida suficientemente buena y la realización de una pluralidad de intereses y concepciones de vivir bien.

Por eso en una comunidad política con carácter ético, sea cual sea su dimensión, las minorías tienen derechos básicos que limitan los derechos de las mayorías. Si la mayoría decide que las mujeres deberían perder su trabajo una vez que se embaracen porque de esa manera las empresas serán más productivas, esa decisión no puede, en ninguna circunstancia adquirir el grado de derecho. Al contrario, las mujeres tienen derechos humanos básicos que no pueden ser violados, aunque las mayorías lo decidan; sean estas las mayorías de un estado, de una nación, de una entidad federativa, de un municipio, o de un pueblo. Pero las minorías no sólo están limitadas por los derechos más básicos como la seguridad física o la inclusión política; sino también por el derecho fundamental de no ser discriminados. Por ejemplo, supongan que la mayoría de los clientes de un centro comercial prefieren realizar sus compras sin la presencia de compradores indígenas. O bien imagínese que la mayoría de los productores y programadores de televisión prefieren ver en pantalla actores, presentadores y anclas de noticias que sean de tez clara. Ese tipo de intereses, aunque no violen derechos políticos o de integridad física o de asociación no pueden traducirse en un derecho, aunque sean compartidos por la mayoría, porque discriminan.

Así pues, los derechos de las mayorías no están limitados por los derechos de las minorías solamente porque vivir bien sea vivir en una sociedad plural; sino porque en una democracia liberal entendida como una comunidad ética, las leyes que regulan nuestra convivencia pacífica no pueden ejercerse de una manera tal que ponga en peligro la dignidad de las personas. En una democracia liberal aun las minorías deben poder apoyar e identificarse con las leyes que regulan nuestra convivencia sin sentir que por ello quedan sometidos a la voluntad de otros o a la suerte (Dworkin, 2001, p. 205; 2011 pp. 13-19). Las instituciones del estado deben tratarnos a todos de manera tal que la vida de ninguna persona o grupo sea considerada como de mayor importancia y eso es verdadero para todos los niveles de gobierno porque las entidades federativas, los municipios o los pueblos no son gobiernos corporativos sino comunidades políticas. Así pues, las instituciones políticas de 
cualquier nivel de gobierno son legítimas cuando al regular la convivencia entre las personas y los grupos no amenazan su dignidad porque tratan a todos de manera tal que la vida de ninguna persona o grupo es considerada más importante que la de los demás. ${ }^{21}$

Sólo en una comunidad política legítima que respete la dignidad de todos es posible que las personas puedan perseguir con autenticidad y responsabilidad sus concepciones de tener una buena vida y vivir bien, porque vivir bien significa vivir en una comunidad que no sacrifique la dignidad de las personas o los grupos para que algunas personas o grupos tengan una buena vida que satisfaga sus intereses y deseos comunes.

Esto no quiere decir que el conflicto no surja cuando las concepciones acerca de vivir bien no coinciden. Pero si quiere decir que las personas están motivadas para ponerse de acuerdo en lo fundamental y dejar que otras personas realicen concepciones distintas del vivir bien, porque oponerse a un arreglo social que posibilite que todos puedan vivir bien, va en contra de la propia posibilidad de vivir bien y tener una buena vida.

\section{Convicciones Morales y Discriminación.}

En la sección anterior he insistido en que aún las unidades comunitarias más pequeñas son comunidades políticas y no meros agregados de individuos, sociedades privadas o asociaciones. En todos esos colectivos es permisible que se persigan fines particulares y se apliquen códigos de conducta o prácticas que son propios de ese colectivo o grupo. Pero las democracias liberales y sus unidades comunitarias constitutivas no son sociedades o asociaciones, sino que son comunidades políticas que no pueden reflejar los propósitos o códigos de unos para ser impuestos a otros, si esta imposición es arbitraria y se ejerce en menoscabo de su dignidad. Pero alguien podría objetar todavía: ¿No es esto de todos modos una renuncia parcial a mis principios, a nuestros principios como miembros de un pueblo o un municipio? Si yo o nosotros genuinamente creemos estar en lo correcto

\footnotetext{
${ }^{21}$ La CPEUM reconoce derechos de autodeterminación política a las comunidades indígenas; pero no a otras minorías. En este artículo permanezco agnóstico sobre si esos derechos debiesen o no extenderse a otras minorías, aunque seguramente la respuesta debería ser coherente con los mismos supuestos acerca de la agencia colectiva sobre de los cuales he construido mi argumento. Gracias a Raúl Rodríguez Eguibar por hacerme notar este punto.
} 
en lo tocante a mis convicciones morales, no estamos claudicando al permitir que otras personas realicen concepciones distintas del vivir bien que a nosotros nos resultan abominables ¿No debemos evitar que otras personas cometan faltas y errores si genuina y responsablemente creemos que tenemos una idea correcta de en qué consiste vivir bien?

La respuesta es que no, o cuando menos no necesariamente. Para explicar por qué, es útil pensar en qué pasa cuando obligamos a otras personas a vivir según nuestras reglas acerca del vivir bien y del darse la buena vida. Obligar a otras personas a vivir bajo nuestras reglas equivale a negarles el derecho de equivocarse y tomar responsabilidad por sus vidas propias, aunque el resultado de que tomen el control de sus propias vidas sea que estas personas tengan que hacerse responsable de sus equivocaciones. Cuando les negamos a otras personas el derecho a responsabilizarse por sus equivocaciones les faltamos al respeto porque ofendemos su dignidad. No los consideramos iguales a nosotros: seres humanos capaces de hacer algo valioso con sus vidas, aunque al final se equivoquen; sino que los consideramos inferiores a nosotros, como si sus vidas fueran menos valiosas.

En muchos casos familiares eso es precisamente lo que significa discriminar a alguien por pertenecer a un grupo o colectivo cuyas prácticas o características los hacen distinguibles y nos resultan intolerables, aberrantes o abominables. ${ }^{22}$ Discriminar hace daño a los miembros de grupos identificados porque significa ofender su dignidad y tratarlo como si su vida fuera inferior a la mía o valiera menos. Aun cuando toleramos ciertos planes de vida, pero decimos que preferiríamos no socializar con gente así o que gente así no pertenezca a nuestra familia, estamos discriminando precisamente porque les atribuimos un valor inferior a esas vidas. Al contrario, discriminar no significa poner ciertos límites a que un grupo o pueblo pretenda extender sus ideas de la moralidad, del vivir bien y del darse la buena vida, al resto de los habitantes de un pueblo o comunidad política. Por ejemplo, yo no discrimino cuando decido entablar una relación sentimental con una persona y no con otra. O cuando busco amigos con intereses afines a los míos. Discrimino cuando identifico a un grupo de personas por alguna cualidad particular, ya sea física como el color de la piel o moral, como la

\footnotetext{
${ }^{22}$ Véase por ejemplo Rodríguez Zepeda (2006).
} 
creencia en una filosofía o en una religión y les niego el derecho a participar en la conformación conjunta de las reglas bajo las cuales debemos convivir todos. Y esto vale para cualquier comunidad política independientemente de su tamaño y alcance. Vale para el ámbito federal, para el estatal y para los municipios y pueblos.

Si fuera posible para mí o para mi grupo influir en las reglas que regulan nuestra convivencia pacífica en el pueblo o el municipio de manera tal que reflejen íntegramente mis convicciones morales y las de mi grupo; entonces todos aquellos que no pertenecen a mi grupo quedarían excluidos. Esta exclusión sería injusta porque les arrebataría la capacidad de hacerse responsables por sus propias elecciones de cómo darse a sí mismos una buena vida y vivir bien. No sólo carecerían del derecho a participar en la formulación conjunta de las reglas bajo las cuales debemos convivir sino que también perderían el derecho a equivocarse y responsabilizarse de sus propias vidas. Esto hace que la discriminación sea sistemática y estructural: se comienza a reproducir en todos los dominios de la vida pública. ${ }^{23}$ Por ejemplo, aquellos a los que se les niega la participación en la normalidad sexual, también se les niega la posibilidad de formar familias construidas alrededor del cariño, la atracción y la solidaridad. Al no poder formar familias no acceden a los beneficios económicos y sociales asociados a la unidad familiar, como seguros médicos y el ahorro conjunto. En ese caso tienen que esconderse en el anonimato que dan las grandes ciudades con lo que pierden el derecho de escoger libremente dónde vivir. O por ejemplo también, aquellos relegados económicamente, quedan segregados geográficamente y no pueden acceder a la tecnología que los aliena aún más del resto de sus compatriotas; por lo que quedan excluidos también culturalmente.

La discriminación provoca exclusión social al negarle a los individuos y los grupos la capacidad de participar como iguales; y la exclusión crea verdaderas periferias de excluidos en lo económico, lo cultural, lo tecnológico lo sexual, lo moral y hasta lo existencial. Estas periferias de excluidos, alienadas del centro, de lo normal de lo aceptado por un grupo dominante imposibilitan que el arreglo que regula la convivencia pacífica entre todos sea legítimo, porque no se trata de una comunidad

${ }^{23}$ Ver “PRONAID” (Consejo Nacional para Prevenir la Discriminación [CONAPRED], 2010). 
ética que posibilite la realización de las concepciones del bien de todos; sino de un arreglo político que posibilita a un grupo dominante tener una buena vida y sentirse como en casa.

Pero quizás el daño más desapercibido que la exclusión hace es el daño le hace a las personas y los grupos que excluyen. No es posible ofender la dignidad de alguien imponiéndole un modo de vida, sin ofender y sacrificar la dignidad propia y con ello la capacidad de vivir bien. Al negarle a alguien la posibilidad de responsabilizarse de su propia vida y de la vida en común con el resto de la comunidad, me convierto en ese tirano contradictorio que afirma tener convicciones morales claras y verdaderas pero que al mismo tiempo niega la posibilidad de la ética pública misma, al someter a los otros a su voluntad y dominar su capacidad de adoptar una concepción ética, aunque ello implique equivocarse. Por eso vivir bien incluye no sólo la responsabilidad de tener convicciones morales y defenderlas, sino también la responsabilidad de apoyar el arreglo político y social que permita que otras personas tengan convicciones morales y que las defiendan a pesar del hecho de que estas convicciones no coincidan con las propias o de que estén al cavo equivocadas.

Hasta aquí quizás he contribuido quizás a catalogar un conjunto pequeño de razones por medio de las cuales podríamos sugerir que se equivocan aquellos que buscan que el municipio o el pueblo, refleje sus convicciones morales a costa de los derechos de los demás. Pero ¿no nos equivocamos nosotros también - hasta cierto punto cuando menos - al imponerles coercitivamente un arreglo constitucional que no les pertenece si les impusiéramos esta interpretación del principio de no-discriminación que impone límites a los intereses de darse una buena vida?

Me parece que esta última objeción es poderosa y temo no poder afrontarla en el espacio que me queda. No parece claro que los miembros de algunos pueblos puedan estar sujetos a la ley de la federación sin perder su dignidad si no son parte activa del proceso que produce, justifica y ejecuta nuestro marco regulatorio. Esto es particularmente importante en el caso de nuestros derechos fundamentales. No es claro que la defensa de los derechos humanos de los miembros de algunos pueblos pueda ejecutarse sin poner en peligro en el intento, algunos derechos humanos de los miembros de los pueblos que, en principio intenta proteger, como por ejemplo la autonomía, la libertad de conciencia, de pensamiento y el derecho de autodeterminación política. 
Pero, aunque el espacio sea escaso, puedo decir lo siguiente. Lo que he dicho hasta ahora puede resumirse en la convicción de que las personas que quieren que las instituciones de su pueblo reflejen sus convicciones lo hacen con base en una idea parroquial de pertenencia. Pero esta idea se realiza más bien en comunidades de interés como clubs y asociaciones privadas. En contraste con los grupos o los clubs que deberían poblar la sociedad civil; lo que coherentemente quiere decir pertenecer a una comunidad política que tiene un carácter ético, radica no sólo en la identidad de uno como miembro de un grupo con intereses comunes (como el de extender sus convicciones morales a los demás) sino en reconocer la pertenencia de los demás y reconciliarse uno mismo con ella, aunque ello signifique aceptar el disenso, el pluralismo y hasta el relativismo moral (Rawls, 2001, p 3). ${ }^{24}$ Hasta cierto punto, el pertenecer a una comunidad política de una democracia liberal, significa el ser sujeto de derechos inviolables e inalienables. Pero lo que la última objeción muestra es que el que pertenecer a cualquier comunidad política con carácter ético sustantivo signifique reconocer a cada miembro como sujeto de estos derechos fundamentales; ello no significa que los miembros de estos pueblos se hayan ya apropiado de esos derechos y esos derechos sean justiciables. Esto no ocurre hasta que los miembros de estos pueblos no toman esos derechos y los hacen suyos para su defensa.

No quiero referirme a los casos en los que los derechos de los miembros de estos pueblos son defendidos, sino más bien al caso como el de la comunidad de Cherán en el que son los propios miembros los que se apropian de esos derechos para la defensa de algo que consideran sustancialmente importante. Los indígenas y habitantes de los pueblos originarios generalmente no han intervenido en pie de igualdad, en la elaboración de la ley que protege sus derechos. Los derechos y las leyes que los protegen deberían ser elaborados de una manera incluyente para ser legítimos. La razón es que una vez que una comunidad de apropia de un derecho humano, para la defensa de sus reclamos colectivos, entonces es difícil que se desconecten de la sistemática y orgánica defensa de los derechos más importantes.

\footnotetext{
${ }^{24}$ Véase por ejemplo Camacho (2016).
} 
El problema es que para que los miembros de los pueblos participen en su defensa primero es necesario que participen en su fundamentación. ${ }^{25}$ Para que los miembros de comunidades indígenas puedan participar de la democracia se necesita establecer los modelos y mecanismos institucionales y de gobernanza para que tengan acceso a las oportunidades que no se presentan de manera espontánea en sus comunidades dada la naturaleza distinta y plural de las sociedades y normatividades en las que viven. Es necesario procurar la elaboración de justificaciones independientes de los derechos humanos mediante razones accesibles y compartibles para los miembros de los pueblos y las comunidades indígenas. La articulación de justificaciones alternativas de los derechos humanos mediante razones accesibles y compartibles sienta las bases para iniciar ese proceso no sólo con el fin de que sean los indígenas mismos los que trabajen en su propia defensa, sino que a la larga sean ellos mismos los que acomoden sus normatividades plurales a los marcos normativos de la federación. Pero eso es materia de otro trabajo.

\section{Conclusiones.}

Es un hecho que ningún arreglo político puede reflejar las convicciones morales de todos y cada uno de los mexicanos; pero tampoco un pueblo puede reflejar las convicciones éticas de todos sus habitantes. Pero entonces la tensión se agrava: ¿Cómo puede un pueblo, con convicciones morales claras y fuertes apoyar e identificarse responsablemente con un arreglo político que sin embargo no puede reflejar nunca íntegramente esas convicciones? Creo que el conflicto presente en aquel dilema puede enfrentarse mejor si hacemos la distinción entre vivir bien y tener una buena vida.

Uno de los aspectos sustanciales de vivir bien es ser parte de una comunidad que establece las condiciones de posibilidad para las personas vivan bien y tengan una buena vida. Pero vivir bien establece límites en la buena vida que nos demos. Cuando entendemos que la igualdad —de

\footnotetext{
${ }^{25}$ Los miembros de los pueblos originarios participan muy escasamente en la elaboración de las reglas bajo las cuales viven ya sea porque dentro de los pueblos se dan regímenes autoritarios o porque en el ámbito federal los mecanismos de participación son poco incluyentes. Una excepción notable a esto es la influencia del ejercito Zapatista con respecto de la reforma del artículo segundo la CPEUM. Muchas gracias a una o un lector(a) anónimo(a) por realizar esta observación.
} 
consideración y de trato- no significa que todos tengamos derecho a que el Estado refleje íntegramente las convicciones y cuando entendemos que no todo interés justifica la creación de un derecho entonces podemos explicar de qué manera apoyamos responsablemente una democracia liberal justa y legítima, aunque no refleje íntegramente todas y cada una de nuestras convicciones morales.

En una comunidad política con carácter ético, sea cual sea su dimensión, las minorías tienen derechos básicos que limitan los derechos de las mayorías. Pero las minorías no sólo están limitadas por los derechos civiles; sino también por el derecho fundamental de no ser discriminados. Pero alguien podría objetar todavía: Si en mi pueblo creemos genuinamente estar en lo correcto en lo tocante a nuestras convicciones morales, ¿no estamos claudicando al permitir que otras personas realicen concepciones distintas del vivir bien que a nosotros nos resultan abominables? Pero esto tampoco es necesario. Obligar a otras personas a vivir bajo nuestras reglas equivale a negarles el derecho de equivocarse y ser responsables.

La discriminación provoca exclusión social al negarle a los individuos y los grupos la capacidad de participar como iguales; y la exclusión crea verdaderas periferias de excluidos en lo económico, lo cultural, lo tecnológico lo sexual, lo moral y hasta lo existencial. Al negarle a alguien la posibilidad de responsabilizarse de su propia vida y de la vida en común con el resto de la comunidad, me convierto en ese tirano contradictorio que afirma tener convicciones morales claras y verdaderas pero que al mismo tiempo niega la posibilidad de la ética pública misma, al someter a los otros a su voluntad y dominar su capacidad de adoptar una concepción ética, aunque ello implique equivocarse.

Finalmente, la última objeción que consideré es poderosa: ¿no nos equivocamos nosotros también al imponerles coercitivamente un arreglo constitucional que prohíbe la discriminación pero que no les pertenece? No es claro que la defensa de los derechos humanos de los miembros de algunos pueblos pueda ejecutarse sin poner en peligro en el intento, algunos derechos humanos de los miembros de los pueblos que, en principio intenta proteger.

Para contestar a esta objeción hay que notar que los pueblos están excluidos también casi siempre de la deliberación y fundamentación de estos derechos. Hay que ver casos como el de la 
comunidad de Cherán, en el que son esos miembros los que se apropian de algunos derechos para la defensa de algo que consideran sustancialmente importante. Pero la invitación a formar parte de la deliberación pública acerca de esos derechos y su justiciabilidad está ausente. Los derechos y las leyes que los protegen deberían ser elaborados de una manera incluyente para ser legítimos. La razón es que una vez que una comunidad de apropia de un derecho humano, para la defensa de sus reclamos colectivos, entonces es difícil que se desconecten de la sistemática y orgánica defensa de los derechos más importantes. Pero El problema es que para que los miembros de los pueblos participen en su defensa primero es necesario que participen en su fundamentación.

El reto siguiente del filósofo social hoy, como el de cualquier persona con convicciones morales fuertes y claras es el siguiente: desarrollar interpretaciones atractivas de sus principios morales que sean convincentes para todos; pero sin que ello implique tratar de imponer una manera de vivir a otros.

\section{Referencias:}

Cámara de Diputados del Honorable Congreso de la Unión (1917). Constitución Política de los Estados Unidos Mexicanos. Diario oficial de la Federación. 2019.

Durkheim, É. (1966). Lecciones de sociología. Buenos Aires: Schapire.

Dworkin, R. (2001). A matter of principle, Oxford: Oxford University Press.

Dworkin, R. (2011). Justice for hedgehogs. Nueva York: Harvard University Press.

Gallie, W. B. (1998). “Conceptos esencialmente impugnados”. Universidad Nacional Autónoma, Instituto de Investigaciones Filosóficas.

Instituto Nacional de Estadística, Geografía e Informática. (2015). Encuesta Intercensal 2015.

Recuperado de: http://www.inegi.org.mx/saladeprensa/aproposito/2016/indigenas2016 0.pdf Kant, I. (1970). Kant: The metaphysics of morals, Cambridge: Cambridge University Press. Mill, J.S., (1997). El Utilitarismo. Madrid: Alianza Editorial.

Moore, M. (2015). A political theory of territory, Ox Oxford University Press.

Rawls, J. (2001). Justice as fairness: A restatement, Harvard: Harvard University Press. 
Searle, J. (1998). Social Ontology and the Philosophy of Society, en Analyse \& Kritik 20, vol 2, pp. 34-47. Walzer, M. (2004). Las esferas de la justicia. Una defensa del pluralismo y la igualdad. Cd. Mx: FCE.

Williams, B. A. O. (2005). In the beginning was the deed: Realism and moralism in political argument, Princeton: Princeton University Press. 